\title{
VARIAÇÃO LEXICAL EM MACAPÁ: UM ESTUDO COMPARATIVO COM O ATLAS LINGUÍSTICO DO AMAPÁ (ALAP)
}

\author{
LEXICAL VARIATION IN MACAPA: A COMPARATIVE STUDY \\ WITH THE AMAPÁ LINGUISTIC ATLAS (ALAP)
}

\author{
Helen Costa Coelho ${ }^{1}$ \\ http://lattes.cnpq.br/6756076129585326 \\ Sara Costa de Matos ${ }^{2}$ \\ http://lattes.cnpq.br/0362831489920490
}

Enviado em: 29/09/2020

Aceito em: 05/10/2020

\begin{abstract}
RESUMO: Este artigo apresenta uma descrição da variação lexical na fala dos moradores da área urbana do município de Macapá em comparação com os dados apresentados pelo Atlas Linguístico do Amapá ALAP (RAZKY, RIBEIRO \& SANCHES, 2017). O referido estudo tem como base os pressupostos teóricos da Sociolinguística e da Dialetologia moderna, bem como da metodologia utilizada para a descrição de dados, a Geolinguística. Para tanto, fez-se uso de autores como Ferreira e Cardoso (1994), Labov (2008), Calvet (2002), Cezário e Votre (2008) e Cardoso (2010). Os dados foram coletados in loco através da aplicação do Questionário Semântico-Lexical (QSL), respectivamente o campo semântico denominado "Convívio e Comportamento Social". A pesquisa seguiu os mesmos parâmetros do Atlas Linguístico do Amapá (ALAP), com o intuito de dar conta das dimensões diatópica, diagenérica e diageracional da variação presentes na fala dos dezesseis colaboradores entrevistados. Os resultados foram descritos em cartografias e são importantes para o desenvolvimento de outras pesquisas dialetológicas, no que diz respeito ao conhecimento da norma lexical de um espaço geográfico, visto que este estudo apresenta dados que comprovam a presença de variantes lexicais para conteúdos semânticos diferentes do que apresenta o ALAP. A exemplo das novas variantes que foram registradas, temos as denominações fumo e enrolado que são novas, em relação ao ALAP, para o item 145, tabaco. Ou ainda murrão e brejeira para o item 146, bagana.
\end{abstract}

Palavras-chave: Dialetologia. Sociolinguística. Variação Lexical.

ABSTRACT: This article presents a description of the lexical variation in the speech of residents of the urban area of the municipality of Macapá in comparison with the data presented by the Amapá Linguistic Atlas - ALAP (RAZKY, RIBEIRO \& SANCHES, 2017). This study is based on the theoretical assumptions of Sociolinguistics and Modern Dialectology, as well as on the methodology used for the description of data, Geolinguistics. For this purpose, authors such as Ferreira and Cardoso (1994), Labov (2008), Calvet (2002), Cezário e Votre (2008) and Cardoso (2010) have been used. Data were collected in loco through the application of the Semantic-Lexical Questionnaire (QSL), respectively the semantic field called "Social Coexistence and Behavior". The survey followed the same parameters of the Amapá Linguistic Atlas (ALAP),

\footnotetext{
1 Mestra em Desenvolvimento Regional pela Universidade Federal do Amapá (MDR/UNIFAP). Especialização em Metodologia do Ensino de Língua Portuguesa e Literatura pela Faculdade de Tecnologia Apoena. Graduada em Letras - Língua Portuguesa com Habilitação em Língua Francesa pela Universidade Federal do Amapá (UNIFAP). Atualmente é Professora do Governo do Estado do Amapá (SEED/AP) e doutoranda no Programa de Pós-Graduação em Letras da Universidade Federal do Pará (PPGL/UFPA).

2 Licenciatura Plena em Letras Língua Portuguesa pela Universidade Federal do Amapá - UNIFAP (2019). Especialização em Docência do Ensino Superior pela Faculdade de Teologia e Ciências Humanas - FATECH (2020). Mestranda no Programa de Pós-Graduação em Letras da Universidade Federal do Amapá PPGLET/UNIFAP (2020).
} 
in order to account for the diatopic, diageneric and diagenerational dimensions of the variation present in the speech of the sixteen employees interviewed. The results were described in cartographies and are important for the development of other dialectical researches, regarding the knowledge of the lexical norm of a geographic space, since this study presents data that prove the presence of lexical variants for different semantic contents than ALAP. As with the new variants that have been registered, we have the denominations smoke and rolled that are new, in relation to ALAP, for item 145, tobacco. Or murrão and brejeira for item 146, bagana.

Keywords: Dialectology. Sociolinguistics. Lexical variation.

\section{INTRODUÇÃO}

O estudo que ora apresentamos integra os dados do Projeto do Altas Linguístico do Amapá (ALAP) iniciado nos meados de 2010 que tem como modelo metodológico os estudos Geossociolinguísticos e teve em 2017, a publicação do Atlas Linguístico do Amapá, trabalho idealizado e executado pelos professores Abdelhak Razky, Celeste Ribeiro e Romário Sanches. Certamente, isso ocasionou uma grande contribuição no cenário de estudos linguísticos amapaenses, pois, a partir desse fato, a sociedade teria acesso a uma gama de dados linguísticos disponíveis para investigação de novos fenômenos linguísticos.

Esta pesquisa tem como objetivo principal descrever as variantes lexicais encontradas no município de Macapá, localizado no estado Amapá. E a partir disso, pretende-se elaborar um estudo comparativo com os dados do ALAP para destacar os itens lexicais que divergem do ALAP. Para isso, a metodologia utilizada corresponde aos mesmos parâmetros utilizados pelo ALAP que, por sua vez, teve como base o Questionário Semântico-Lexical (QSL) elaborado pelo Comitê Nacional do Atlas Linguístico do Brasil - ALiB (2001). Com o intuito de dar conta das dimensões diatópica, diagenérica e diageracional da língua falada, essa investigação se voltou apenas para o campo semântico denominado "Convívio e comportamento social", do referido questionário.

O estado do Amapá localizado ao norte do Brasil e é o único, em território brasileiro, que não tem ligação por rodovias com os demais Estados do país. Conta com dezesseis municípios e uma população de 861.773 , segundo estimativa populacional de $1^{\circ}$ de julho de 2020 do Instituto Brasileiro de Geografia e Estatística (IBGE), Macapá é o município mais populoso e possui 512.902 habitantes distribuídos em um território de $6.563,959 \mathrm{~km}^{2}$.

Esse artigo se pauta na teoria da variação de William Labov (1960) e nos estudos dialetais do português brasileiro, conforme preconiza Ferreira e Cardoso (1994), que utiliza a Geolinguística moderna, como metodologia de descrição de dados através de cartografias. Outros estudiosos que se desdobram nos estudos da língua em seu uso real também contribuem para essa pesquisa como: Calvet (2002), Cezário e Votre (2008), Cardoso (2010), Tarallo (1999). Assim este trabalho será dividido em 5 partes, sendo a primeira para a introdução, a segunda da conta do aporte teórico, a terceira a apresenta os instrumentos de pesquisa, a quarta parte mostra os resultados e o último tópico destaca as considerações finais.

\section{O ESTUDO DA VARIAÇÃO}

Para iniciar as discussões, análises e apontamentos das variações do léxico que ocorrem no estado do Amapá, especificamente na capital Macapá, acreditamos ser necessário apresentar conceitos fundamentais que servem de base teórica para esta investigação.

\subsection{A RELAÇÃO ENTRE SOCIOLINGUÍSTICA E DIALETOLOGIA}

No final do século XIX, antes do advento da Sociolinguística, a Dialetologia tinha por objetivo descrever os dialetos, mas se limitava às variações geográficas ocorridas principalmente nas 
áreas rurais. Ou seja, a Dialetologia estava encarregada das variações linguísticas de forma a traçar fronteiras geolinguísticas no Brasil, como afirma Ferreira e Cardoso (1997, p. 18).

Essa ciência, em princípio, considerava apenas a variação diatópica (espacial) e posteriormente como era de se esperar, seguiu o curso das línguas e das sociedades que estão em constante processo de evolução, mudanças e reformulações. Desse modo, a Dialetologia se modernizou, segundo Cardoso (2010), ampliou seus horizontes, deixando de ser apenas diatópica para passar a atender uma gama maior da diversidade linguística. Com essas mudanças, passou-se a observar também variações mais complexas de caráter social, tais como: a variação diageracional (faixa etária), diagenérica (sexo), diassexual ${ }^{3}$ (gênero ou sexo), diastrática (classe social) e diafásica (variações estilísticas).

Para dar conta dos estudos da fala, a Dialetologia faz uso da Geolinguística (também conhecida como Geografia Linguística) que surge como o método de investigação comumente usado nos Atlas Linguísticos. O papel fundamental desse modelo teórico-metodológico, desenvolvido pelos dialetólogos, visa documentar as variações das línguas através da técnica da cartografia, correspondente à organização dos resultados das pesquisas em mapas geográficos, como afirma Coseriu (1982):

\begin{abstract}
A Geolinguística pressupõe o registro em mapas especiais de um número relativamente elevado de formas linguísticas (fônicas, lexicais ou gramaticais) comprovadas mediante pesquisa direta e unitária numa rede de pontos de um determinado território, ou que, pelo menos, tem em conta a distribuição das formas no espaço geográfico correspondente à língua, às línguas, aos dialetos ou aos falares estudados (COSERIU, 1982, p. 79).
\end{abstract}

Desse modo é possível, além de registrar, comparar as variações da língua com maior facilidade, como a descrição do falar dos amapaenses que será feito neste trabalho. A partir dessa perspectiva, entende-se que as bases conceituais deste trabalho se firmam também na geografia linguística.

Apesar de a Dialetologia e a Geolinguística serem frequentemente tomadas como a mesma coisa e serem confundidas, Ferreira e Cardoso (1994) destacam a importância de entender que a Dialetologia é uma ciência que faz uso da Geografia Linguística como método de descrição e comparação de dados. Compreende-se que o papel do Geolinguística torna-se indispensável ao passo que se faz a documentação das memórias linguísticas de um povo. Esse foi o método de descrição de dados adotado pelo Atlas Linguístico do Brasil (CARDOSO et al., 2014) e em seguida pelo Atlas Linguístico do Amapá (RAZKY, RIBEIRO, SANCHES, 2017).

Após a Dialetologia já ter tomado frente nos estudos da variação da língua, em 1960, outra ciência com apelos semelhantes entra em evidência: a Sociolinguística, que geralmente é confundida ou tomada como equivalente à Dialetologia. Elas se diferem em alguns pontos, já que "a Sociolinguística [...] que tem como interesse central, como o próprio nome sugere, estudar a variação linguística à luz de causas sociais, e a dialetologia interpretar os fatos linguísticos segundo as diferenças sociais, profissionais, de nível de escolaridade, etária, de sexo, etc.”, como explica Ferreira e Cardoso (1994, p. 18).

Para Labov (2008), essa ciência que foca na língua em uso nas comunidades de fala é denominada "de forma redundante de Sociolinguística", para a qual argumenta que, "a língua é uma forma de comportamento social [...] crianças mantidas em isolamento social não usam a língua; ela é usada por seres humanos num contexto social, comunicando suas necessidades, ideias e emoções uns aos outros" (LABOV, 2008, p. 215).

\footnotetext{
${ }^{3}$ Cabe destacar que, para este estudo, adotamos a nomenclatura utilizada pelo modelo metodológico empregado no Projeto do Atlas Linguístico do Brasil (ALiB, 2001), para realizar a identificação e a descrição dos usos linguísticos dialetais de homens e mulheres. Em outras palavras, considerando a nossa proposta investigativa com base nos moldes do ALiB e do ALAP, compreendemos que o termo mais apropriado seria a dimensão diassexual.
} 
Enveredando por esse caminho, Labov (2008), um dos impulsionadores da Sociolinguística, cria o modelo de análise chamado de Teoria da Variação e Mudança Linguística/ Sociolinguística Quantitativa/ Sociolinguística Variacionista, que se consolida nos Estados Unidos em 1960. Essa teoria investiga as relações entre língua e sociedade partindo do princípio de que as línguas são passíveis de mudanças, pois são administradas por seres humanos de diferentes procedências sociais e, assim, estão expostos às realidades e situações comunicativas diversas umas das outras. E, para além dos aspectos extralinguísticos (envolvendo idade, gênero, profissão, classe social), a referida teoria trabalha a concepção de língua em uma vertente diacrônica, observando a historicidade.

Essa perspectiva, no entanto, foi de encontro às abordagens formalistas que vigoravam nos estudos linguísticos defendidos há mais de meio século por Ferdinand Saussure e Chomsky, onde se admitia a língua apenas na perspectiva sincrônica e isolada dos fatos sociais.

Retomando a teoria diacrônica, seguindo essa linha, Calvet (2002) corrobora com Labov (2008) ao destacar que "Sociolinguística vai partir do princípio de que a variação e a mudança são inerentes à língua, e por isso, devem ser levadas em conta na análise linguística." A Sociolinguística é definida, segundo Cesário e Votre (2008) como "uma instituição social", ou seja, o estudo da língua deve levar em conta o contexto de produção assim como outros aspectos extralinguísticos. Então, o modelo teórico-metodológico considerado na sociolinguística variacionista preza pelas formas linguísticas em transformação, sendo resultantes das mudanças orgânicas da vida nas comunidades de fala. Dessa forma busca-se sistematizar e organizar a gama de variedades que podem seguir.

Tarallo (1999) enfatiza o que são exatamente alguns conceitos básicos que moldam a Sociolinguística, conhecidos por variáveis e variantes linguísticas: "variantes linguísticas, são, portanto, diversas maneiras de se dizer a mesma coisa em um mesmo contexto, e com o mesmo valor de verdade. Ao conjunto de variantes dá-se o nome de variável linguística" (TARALLO, 1999, p. 8).

Apesar de existirem vários fatores externos à língua que podem influenciar no ato de fala, nos estudos sociolinguísticos é possível ordenar essas variações. O sociolinguista trabalha com a análise de dados a partir de formas pautadas em determinada organização. Labov (2008), na tentativa de estabelecer padrões e sistematizar o "caos" que a língua falada pode apresentar, cria o modelo teórico de análise que busca estabelecer as possibilidades de variações.

Alkimin (2006) destaca alguns fatores que devem ser considerados nos sujeitos pesquisados que geram variação linguística: podendo ser internos (semânticas, sintáticas, morfológicas, fonético-fonológicas) ou externos (idade, sexo, etnia, localização espacial, religião, classe social, profissão, escolaridade, renda, grau de formalidade e tensão discursiva). A autora explora apenas as variações externas do tipo diatópica (espacial), onde nesta vertente se considera o espaço geográfico do informante, diagenérica (que tem a ver com o sexo, para diferenciar entre homem e mulher), e diageracional (faixa etária considerada como fator de variação).

Em todo caso a maioria dos estudos de ambas as ciências, dialetologia e sociolinguística, sempre se esbarram, pois elas têm como o objetivo principal em comum, estudar a diversidade da língua falada como aponta Cardoso e Ferreira (1994, p. 19):

$\mathrm{Na}$ verdade, definir objetivo e metas dos vários ramos da ciência da linguagem, como, aliás, em qualquer ciência, é sempre muito difícil porque são fluidos ou pouco nítidos esses limites, mais fluidos e pouco nítidos se tornam quando se fala em dialetologia e sociolinguística que têm - ambas - como objetivo maior o estudo da diversidade da língua dentro de uma perspectiva sincrônica e concretizada nos atos da fala. (FERREIRA, CARDOSO, 1994, p. 19).

Nesse sentido, compreendemos a importância das duas áreas do conhecimento para compreender os fatores linguísticos e extralinguísticos que envolvem a relação da língua no contexto social. Pois mediante tais estudos, é possível cotejar com outros falares de outras regiões e comunidades do Brasil e do mundo. 


\subsection{ATLAS LINGUÍSTICO DO BRASIL - (ALiB)}

O marco inicial para o desenvolvimento do projeto Atlas Linguístico do Brasil (ALiB), baseado na Sociolinguística e Dialetologia, foi o Seminário "Caminhos e Perspectivas para a Geolinguística no Brasil”, realizado na Universidade Federal da Bahia, em 1996. O Atlas Linguístico do Brasil é um projeto pensado em âmbito nacional para criar uma linha imaginária que marca as variações linguísticas por regiões. Usando de questionários divididos em quinze grupos semânticos que atende a vários níveis de variação da língua (fonológicos, morfológicos, sintáticos, semânticos e lexicais), o projeto Atlas Linguístico do Brasil coletou dados em 250 localidades brasileiras de Norte a Sul do país. Razky, Ribeiro e Sanches (2017) destacam os elementos que compõem e o foco principal de um Atlas Linguístico:

[...] registram as diferentes variações por que passa uma língua: fônicas, morfossitánticas, léxico-semânticas, discursivo-pragmáticas. Seja qual for a finalidade do atlas, seu foco toma por base as evidências que caracterizam as realizações da língua viva, de uso real, preservando os dialetos e as manifestações características de uma região, os quais, muitas vezes, são ameaçados pela propagação exacerbada da variedade culta da língua (RAZKY, RIBEIRO, SANCHES 2017. p. 12).

Assim, é perceptível que a Dialetologia e a Sociolinguística caminharão juntas compartilhando do mesmo objeto de estudo: a língua viva. Então, quando se trabalha na produção de um Atlas Linguístico existe a necessidade de colaboração entre essas duas grandes ciências, Dialetologia (Geolinguística) e Sociolinguística tal qual ocorreu com o Atlas Linguístico do Brasil que considerou as variações diatópicas e sociais, tornando-se um trabalho pluridimensional.

Logo, entende-se que o papel fundamental de um atlas linguístico é descrever e documentar as variações de toda natureza que ocorrem na língua viva, e em todos os seus níveis, seja fônico, lexical, semântico, morfológico, fonológico ou sintático. E desse modo criar possibilidade de entendimento das variações em sua plenitude ao mesmo tempo em que, por meio do conhecimento, desconstroem-se estigmas jogados sobre todas as variações que fogem a norma culta. Para a produção do ALiB, constituiu-se um comitê cujos integrantes são autores de Atlas Estaduais. Os membros do comitê são atualmente: Jacyra A. Mota (UFPB); Silvana S. C. Ribeiro (UFPB); Abdelhak Razky (UFPA); Aparecida N. Isquerdo (UFMT); Conceição Ma de Araújo (UFMA); Fabiane C. Altino (UEL); Felício W. Margotti (UFSC); Marcela M. T. Paim (UFBA); Ma do Socorro S. Aragão (UFCE/UFPB); Marilucia B. de Oliveira (UFPA); Rejane C; P. Reis (UFMS); Valter P. Romano (UFL); Vanderci de A. Aguilera (UEL), dentre outros.

Esse macro projeto veio trazer grandes resultados, visto que depois dessa iniciativa vários outros atlas regionais foram elaborados e surgiram muitos outros projetos que ainda se encontram em construção. Cabe enfatizar que cada projeto se baseia nos procedimentos metodológicos estabelecidos pelo Projeto ALiB, com o intuito de padronizar as pesquisas de caráter geolinguístico.

Uma contribuição importante do comitê do ALiB foi a construção do questionário semântico lexical contendo 202 (duzentas e duas) perguntas divididas em 14 (quatorze) grupos semânticos que visam atender a todas as áreas da vida e atividades humanas, são eles: Acidentes geográficos, fenômenos atmosféricos, Astros e tempo, Atividades agropastoris, Fauna, Corpo bumano, Ciclos da vida, Convivio e comportamento social, Religião e crenças, jogos e diversões infantis, Habitação, Alimentação e coẓinha, Vestuário e Acessórios, Vida urbana. Esse questionário foi adotado como base para as perguntas a serem aplicadas na recolha dos dados para a elaboração de novos Atlas Linguísticos, como o ALAP, assim como em trabalhos de pequeno porte. 


\subsubsection{ATLAS LINGUÍSTICO DO AMAPÁ (ALAP) ${ }^{4}$}

Quando se fala em estudos dialetológicos e sociolinguísticos na região Norte, é preciso dizer que ainda existe muito a ser explorado, visto que a região amazônica possui grande diversidade linguística por conta das muitas influências no seu processo de formação que reflete até hoje na língua e cultura nortista. No Amapá, Ribeiro e Sanches (2018, p. 205) fizeram um mapeamento dos estudos Geolinguísticos do Estado e constataram que na década de 2008 a 2018, apenas 09 (nove) trabalhos foram publicados na área da Geolinguística, comprovando o quanto ainda é preciso difundir a pesquisa das línguas faladas no Amapá.

Dos 09 (nove) trabalhos, o último e maior já realizado sobre a diversidade linguística no território amapaense, foi o livro Atlas Linguístico do Amapá - ALAP, pensado e realizado pelo professor Abdelhak Razky, da Universidade Federal do Pará, professora Celeste Maria da Rocha Ribeiro, da Universidade Federal do Amapá, e professor Romário Duarte Sanches, da Universidade Estadual do Amapá. A tendência é que a partir do Atlas haja um aumento nos números de trabalhos na área da sociolinguística e da dialetologia.

Com o Atlas é possível ter uma visão mais ampla das condições linguísticas no Amapá, em que se tem como principais objetivos a descrição e o mapeamento do Português brasileiro falado em 10 (dez) municípios do Estado, de forma a evidenciar as variedades linguísticas de aspectos fonético-fonológicos e semântico-lexicais característicos de cada localidade. Com o atlas buscouse

[...] contribuir para o entendimento coerente da língua e de suas variantes visando também eliminar a visão distorcida que tende a privilegiar uma variante apenas e estigmatizar as demais, em que predominam somente as variantes preconizadas pela variedade culta [...] (RAZKY, RIBEIRO, E SANCHES, 2017, p. 12).

Ribeiro e Sanches (2013, p. 278) ressaltam que, além de servir como um método de documentar e registrar a língua, um atlas também serve "[...] como recurso de ensino e aprendizagem da língua materna, pois refletem a diversidade e a heterogeneidade dialetal, concretizadas em diversas situações comunicativas, de diferentes campos linguísticos".

\section{INSTRUMENTOS E MÉTODOS DE PESQUISA}

Neste tópico serão descritas a metodologia e as técnicas de pesquisas que foram usadas para a seleção dos pontos de inquéritos, colaboradores, corpus e ${ }^{5}$ execução da pesquisa e documentação dos dados. É relevante destacar que os pontos citados foram escolhidos com base nos mesmos critérios do ALAP, visto que se trata de uma pesquisa que irá comparar os dados e, portanto, se faz necessária adoção dos mesmos critérios.

\subsection{PONTOS DE INQUÉRITOS}

\footnotetext{
4 É importante destacar que esse estudo se volta apenas para o livro Atlas Linguístico do Amapá que foi publicado em 2017, e não para o Projeto Atlas linguístico do Amapá, o projeto continua, fomentado e desenvolvendo trabalho e atividades.

5 Justifica-se a classificação dos bairros Cidade Nova e Laguinho na Zona Sul por estarem mais próximos da referida área e, principalmente, pela facilidade em encontrar o falante de acordo com o perfil estabelecido para este estudo, bem como para fazer um equilíbrio no quantitativo dos dados já coletados nos bairros da Zona Norte. Cabe destacar que estes dois bairros foram os primeiros onde a pesquisa de campos foi realizada e por questões de falta de tempo, não conseguimos efetuar a pesquisa em outros bairros da Zona Sul, por esse motivo, optamos em agrupar os bairros Cidade Nova e Laguinho junto com os bairros da Zona Sul na classificação deste estudo.
} 
A escolha dos pontos de inquérito foi pensada visando abraçar a maior extensão possível da cidade de Macapá. Por esse motivo, consideramos a divisão geográfica por Zonas Sul e Norte do Município de Macapá, onde cada ponto representa um bairro diferente para se chegar o mais próximo possível do falar real dos amapaenses. Com isso foram selecionados 02 (dois) pontos de inquéritos, sendo 08 (oito) na Zona Sul (nos bairros Cidade

Nova, Laguinho, Pedrinhas, Zerão, Jardim Marco Zero, Nova Esperança, Santa Inês e Buritizal) e outros 08 (oito) na Zona Norte (nos bairros Renascer, Jardim Felicidade, Boné Azul, Infraero I, Infraero II, Brasil Novo, Loteamento Açaí e Loteamento Amazonas).

\subsection{PERFIL DOS COLABORADORES}

Ao considerarmos as variações diatópica (espacial), diagenérica (sexo) e diageracional (faixa etária), definimos o seguinte perfil dos colaboradores: 16 (dezesseis) informantes que se distribuem proporcionalmente pelo sexo, ou seja, 08 (oito) homens e 08 (oito) mulheres, distribuídos em 2 (duas) faixa etárias sendo a primeira de 18 (dezoito) a 30 (trinta) anos, e a segunda de 50 (cinquenta) a 75 (setenta e cinco), quanto ao grau de escolaridade, os colaboradores podem ser identificados como ensino fundamental, completo ou incompleto. As entrevistas aconteceram na casa dos entrevistados em um horário escolhido por eles definido. O quadro 1 evidencia o perfil dos informantes estabelecido para esta pesquisa:

Quadro 1: Perfil dos informantes

\begin{tabular}{|c|c|c|c|c|}
\hline \multicolumn{5}{|c|}{ Macapá } \\
\hline Informante & Localização (zona) & Sexo & Faixa etária & Escolaridade \\
\hline 02 & Sul & Masc. & $18-30(\mathrm{I})$ & E. Fundamental Completo \\
\hline 02 & Norte & Masc. & $18-30(\mathrm{I})$ & E. Fundamental Completo \\
\hline 02 & Sul & Masc. & $50-75(\mathrm{II})$ & E. Fundamental Completo \\
\hline 02 & Norte & Masc. & $50-75(\mathrm{II})$ & E. Fundamental Incomp. \\
\hline 02 & Sul & Fem. & $18-30(\mathrm{I})$ & E. Fundamental Incomp. \\
\hline 02 & Norte & Fem. & $18-30(\mathrm{I})$ & E. Fundamental Incomp. \\
\hline 02 & Sul & Fem. & $50-75(\mathrm{II})$ & E. Fundamental Incompleto \\
\hline 02 & Norte & Fem. & $50-75(\mathrm{II})$ & E. Fundamental Incompleto \\
\hline 16 & \multicolumn{5}{|c|}{ Total de colaboradores nas duas zonas } \\
\hline
\end{tabular}

Fonte: Criação das autoras (2020).

\subsection{INSTRUMENTOS DE PESQUISA E SELEÇÃO DO CORPUS}

O corpus escolhido como instrumento de pesquisa constitui as respostas dadas as questões do "Convívio e Comportamento Social", extraído do (QSL) do ALAP, que por sua vez pautou-se no questionário do ALiB. Assim como no ALAP, para esse estudo, apenas 09 (nove) itens lexicais do campo semântico "Convívio e Comportamento Social" foram considerados, a saber:136-A pessoa que fala demais?; 138-A pessoa que não gosta de gastar seu dinheiro e, às vežes, até passa dificuldades para não gastar?; 139-A pessoa que deixa as suas contas penduradas?; 140-A pessoa que épaga para matar alguém?; 141-O marido que a mulher passa para trás com outro homem?; 142-Mulher que se vende para qualquer homem?; 144-Que nomes dão a uma pessoa que bebeu demais?; 145-Que nomes se dão ao cigarro que as pessoas faziam antigamente, enrolado à mão?; 146-O resto do cigarro que se joga fora?"

Justificamos a escolha pela aplicação do QSL justamente pelo fato de que nesse tipo de questionário se encontram um maior número de respostas, ainda que sejam flexíveis e seus informantes incentivados a usarem termos que não sejam ativos do vocabulário, conforme Razky (2017). Contudo, é imprescindível que se insista na captura da diversidade lexical da comunidade visto que, segundo Neves (2005, p. 645) "no léxico, não apenas estão recortados os dados de uma realidade externa, mas também está espelhada tudo aquilo que, pela vivência em interação, uma comunidade cria e constrói”"

https://periodicos.unifap.br/index.php/letras

Macapá, v. 10, n. 1, $1^{\circ}$ sem., 2020 


\subsection{DESCRIÇÃO DE DADOS E CARTOGRAFIA LINGUÍSTICA}

Após a aplicação do referido questionário in loco e de posse dos inquéritos, os resultados foram filtrados para selecionar apenas as amostras com mais variantes para necessário descrever. Dos 09 (nove) itens semânticos pesquisados apenas quatro serão descritos neste artigo, pois foram os que demostraram mais variações semântico-lexicais em comparação aos dados do ALAP. Com o fim de detalhar as informações contidas nas cartas linguísticas, elaboramos a seguinte carta-base:

Figura 01: Carta-Base

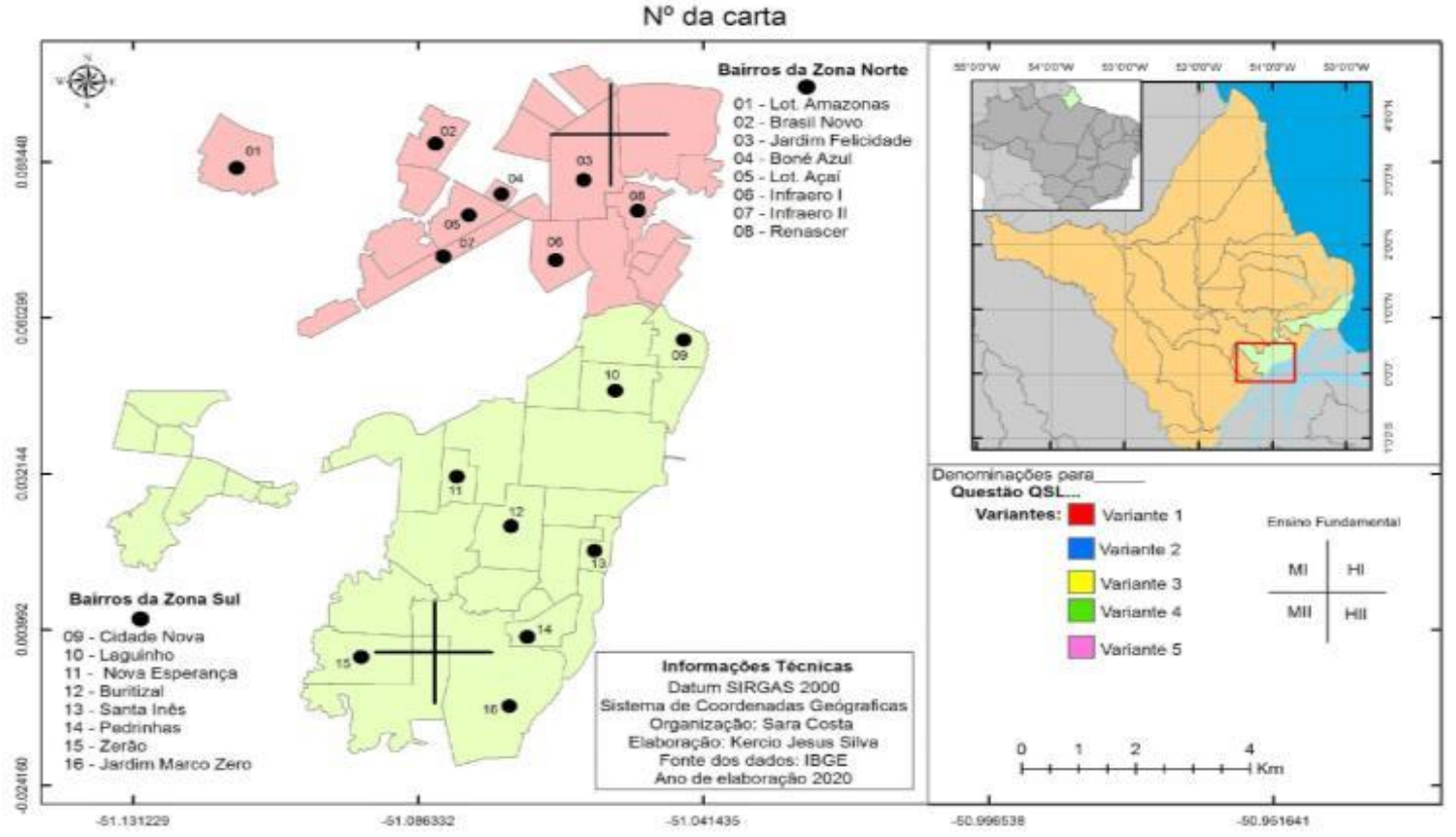

Fonte: criada pelas autoras (2020)

a) $\mathrm{Na}$ parte superior central da imagem está localizado o título que é o número da carta de acordo com a ordem de sua elaboração, seguida pela a letra L que representa o campo de estudo, nesse caso Lexical, exemplo: "CARTA L01"; No canto superior à direita lê-se a localização do estado do Amapá no Brasil e a localização de Macapá dentro do estado do Amapá. Dentro do mapa está destacado, com um quadrado vermelho, a zona de estudo de Macapá, apenas a área urbana;

b) Ainda no canto direito, na borda inferior, está descrita a denominação mais recorrente para aquela questão, segundo o ALAP;

c) Abaixo da denominação estão descritas as respectivas questões com a mesma numeração do questionário aplicado;

d) Abaixo da questão, ainda do lado direito, estão elencadas as variantes na ordem decrescente de produção, ou seja, da mais recorrente para a que menos é utilizada. Além disso, cada variante é marcada com uma cor de acordo conforme indicação apresentada na a tabela 1 : 
Tabela 1: Cores para cartas lexicais (RGB)

\begin{tabular}{|c|c|c|c|c}
\hline Cores & Variante & $\mathrm{R}$ & $\mathrm{G}$ & $\mathrm{B}$ \\
\hline & Variante 1 & 255 & 0 & 0 \\
\hline & Variante 2 & 0 & 0 & 0 \\
\hline & Variante 3 & 255 & 255 & 0 \\
\hline & Variante 4 & 0 & 150 & 201 \\
\hline & Variante 5 & 248 & 0 & 0 \\
\hline & Variante 6 & 255 & & 247 \\
\hline
\end{tabular}

Fonte: criada pelas autoras (2020)

e) No canto inferior direito está a cruz com os critérios de variações a serem observados e neles constam os seguintes símbolos e seus respectivos significados: MI, MII, HI, HII e F que indicam o perfil dos colaboradores, onde se lê $\mathrm{MI}=$ mulher da primeira geração, $18 \mathrm{a}$ 30 anos; MII = mulher da segunda geração, 50 a 72 anos; $\mathrm{HI}=$ homem da primeira geração, de 18 a 30 anos e HII = homem da segunda geração, de 50 a 75 anos, outro aspecto que é considerado é a escolaridade, todos os colaboradores correspondem ao $\mathrm{F}=$ Fundamental;

f) O lado esquerdo e central da carta é preenchido com o mapa da Zona Urbana do território amapaense. Esse território está dividido em duas Zonas diferenciadas pelas cores rosa (representando a Zona Norte) e verde (representando a Zona Sul). Os bairros onde foram coletados os dados estão sinalizados em pontos pretos;

g) Ao lado do mapa da Zona Norte e da Zona Sul estão as legendas representando os bairros pesquisados;

h) Dentro do mapa da cidade existem duas cruzes, cada uma em um ponto de inquérito, que serão preenchidas com as respectivas variantes. Cada cruz terá 08 (oito) quadros e cada um corresponde à informação prestada por cada informante.

\section{APRESENTAÇÃO E DISCUSSÃO DE DADOS}

A descrição dos dados será feita por meio de cartografias conforme o método Geolinguístico, as cartas seguirão uma análise de cada uma das lexias investigadas. Entretanto, destacamos que as questões do QSL: "140. A pessoa que é paga para matar alguém?"; "141. O marido que a mulher passa para trás com outro homem?"; "144. Que nomes dão a uma pessoa que bebeu demais?" não são descritas neste trabalho, por não haver variação significativa desses vocábulos, ou seja, durante a pesquisa as variantes coletadas foram as mesmas que aparecem no ALAP, se tornando desnecessária a repetida descrição.

\subsection{Descrição das cartas selecionadas.}

\subsubsection{Tagarela}

Os resultados representados na carta abaixo mostram as seguintes variantes para tagarela: 


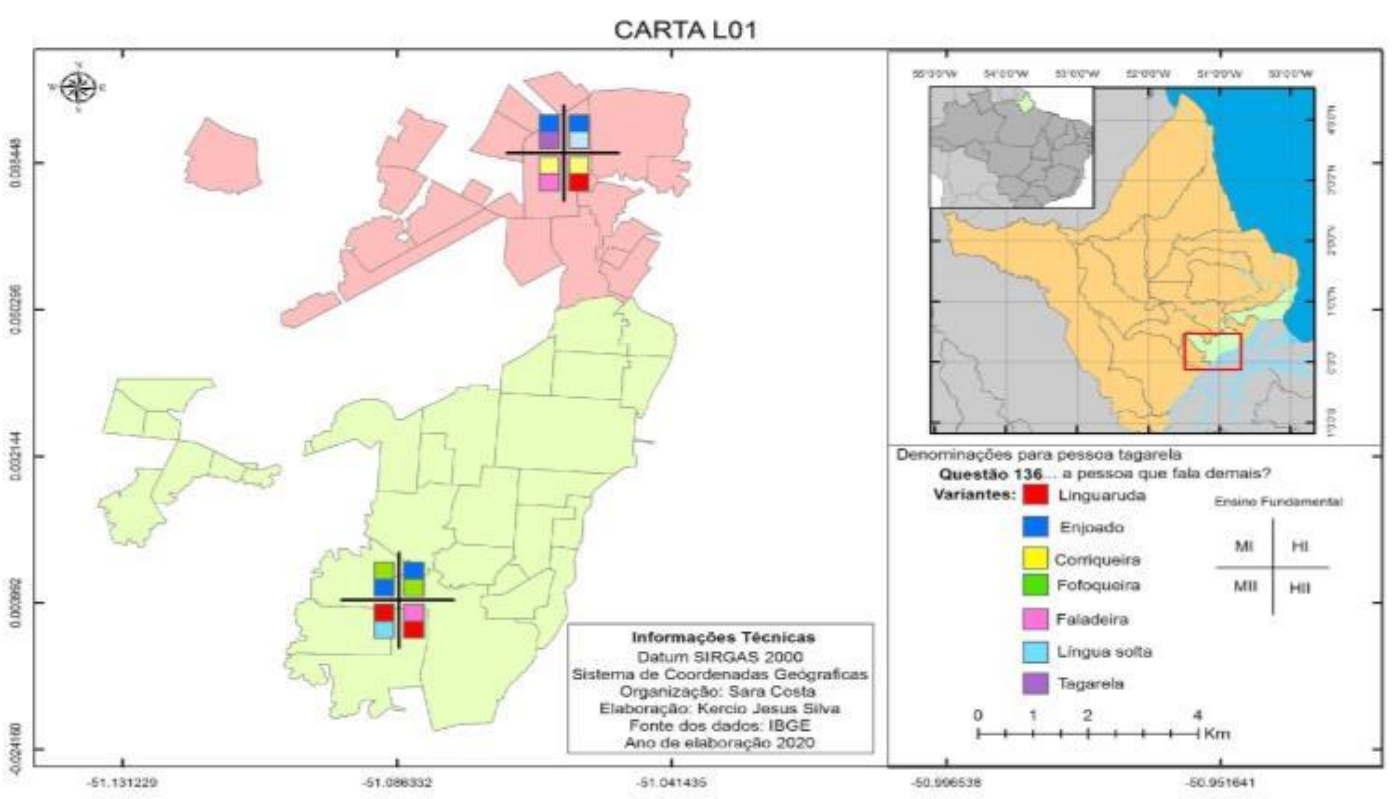

Fonte: criada pelas autoras (2020)

$\mathrm{Na}$ Carta L01, referente à questão 136 do QSL foram registradas 07 (sete) variantes foram: linguaruda, faladeira, fofoqueira, enjoado, corriqueira, tagarela e lingua solta. Considerando a variação diageracional entre os informantes da primeira geração, destacam-se o uso de 02 (duas) ocorrências de fofoqueira, 04 (quatro) vezes enjoada e apenas 01 (uma) de tagarela. Enquanto na segunda geração existe uma predominância das variantes linguaruda, que ocorreu 03 (três) vezes, corriqueira informada 02 (duas) vezes e faladeira também com 02 (duas) ocorrências. A variante tagarela foi a única informada por ambas as gerações sendo 01 (uma) vez pelos mais jovens e 01 (uma) vez pelos idosos. Do ponto do de vista da variação diagenérica, observa-se que todas as variações encontradas são usadas tanto por homens quanto por mulheres, exceto a variante tagarela que foi informada apenas pelas mulheres.

Em comparativo com o mapeamento do ALAP as variantes que se destacam são: linguaruda, fofoqueira, corriqueira e língua solta. Pois estes são vocábulos que não aparecem na descrição do ALAP como termos frequentes. As denominações mais comuns segundo o ALAP, no município de Macapá, correspondem a 33,3\% tagarela e 33,3\% barulhento. Os outros 33,3\% se encaixam no grupo das variantes pouco produtivas. Tais informações podem ser visualizadas a partir do seguinte quadro comparativo:

Quadro 2: Dados comparativos com o ALAP

\begin{tabular}{|c|c|c|c|}
\hline Variantes & ALAP & Zona Sul - Macapá & Zona Norte - Macapá \\
\hline Tagarela & $\mathrm{X}$ & - & $\mathrm{X}$ \\
\hline Faladeira & $\mathrm{X}$ & $\mathrm{X}$ & $\mathrm{X}$ \\
\hline Enjoada & $\mathrm{X}$ & $\mathrm{X}$ & $\mathrm{X}$ \\
\hline Fofoqueira & - & - & $\mathrm{X}$ \\
\hline Corriqueiro & - & $\mathrm{X}$ & $\mathrm{X}$ \\
\hline linguaruda & - & $\mathrm{X}$ & $\mathrm{X}$ \\
\hline Língua Solta & - & - & - \\
\hline Barulhento & $\mathrm{X}$ & - & - \\
\hline Papagaio & $\mathrm{X}$ & - & - \\
\hline Bocudo & $\mathrm{X}$ & & \\
\hline
\end{tabular}

Fonte: Criado pelas autoras (2020) 


\subsubsection{Jarãna.}

O item jarãna refere-se à questão 138 do QSL e apresentou as seguintes variantes:

Figura 03: Ocorrências para o item jarãna

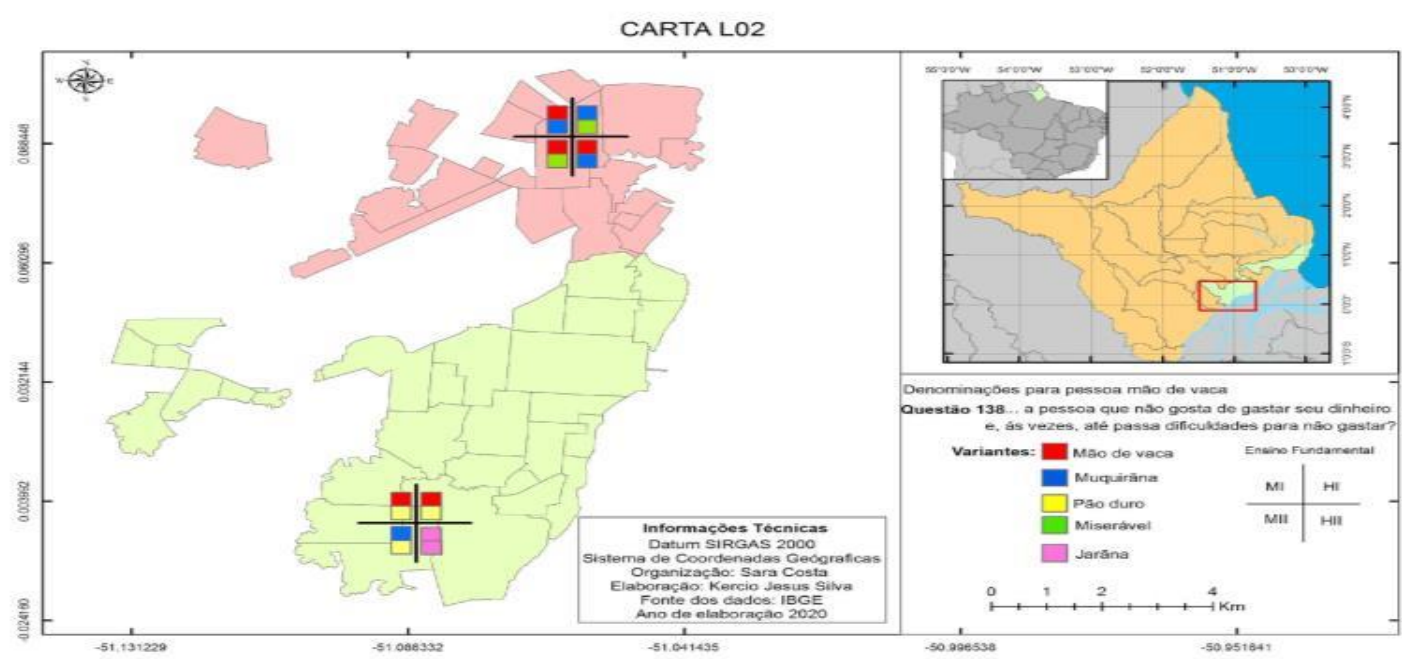

Fonte: criada pela autora (2020)

A Carta L02, referente a questão 138 do QSL, apresentou 05 (cinco) variantes diferentes: Mão de Vaca, Muquirãna, Pão duro, Miserável e Jarãna. Sendo muquirãna e pão duro 02 (duas) variantes que não aparecem como produtiva nas amostras do ALAP, mas ocorrem. O Atlas do Amapá ainda indica que a maior parte dos macapaenses usam a variação jarãna, aqui a variante com o maior número de ocorrências é mão de vaca.

No entanto, a variante jarãna é a única que mostra um de grau preferência para o uso. Foi utilizada apenas por homens da segunda geração de acordo com a variante diageracional. As demais amostras encontradas para essa questão são utilizadas com a mesma frequência na primeira e segunda geração, não sendo possível fazer uma divisão diagenérica, conforme descrito ao lado: A variação diageracional mostra que os falantes da primeira geração usaram Mão de Vaca por 03 (três) vezes, Muquirãna 02 (duas) vezes, Pão duro 02 (duas) vezes, Miserável 01 (uma) vez. Entre os informantes idosos ocorreram as seguintes variantes Mão de Vaca 02 (duas) vezes, Muquirãna 02 (duas) vezes, Pão duro e Miserável 01 (uma) vez, jarãna 02 (duas) vezes.

Considerando a variação diagenérica, as mulheres fizeram uso das seguintes léxias Mão de Vaca 03 (três) vezes, Muquirãna 02 (duas) vezes, Pão duro 02 (duas) vezes, Miserável 02 (duas) vezes. Já entre os homens Mão de V aca aparece 02 (duas) vezes, Muquirãna 02 (duas) vezes, Pão duro 01 (uma) vez, Miserável 01 (uma) vez e Jarãna 02 (duas) vezes. Conforme os dados apresentados no quadro 3:

Quadro 3: Dados comparativos com o ALAP

\begin{tabular}{|l|c|c|c|}
\hline \multicolumn{1}{|c|}{ Variantes } & ALAP & Zona Sul - Macapá & Zona Norte - Macapá \\
\hline Mão de Vaca & $\mathrm{X}$ & $\mathrm{X}$ & $\mathrm{X}$ \\
\hline Jarãna & $\mathrm{X}$ & $\mathrm{X}$ & $\mathrm{X}$ \\
\hline Miserável & $\mathrm{X}$ & - & - \\
\hline Mão Fechada & $\mathrm{X}$ & - & - \\
\hline Rocha & $\mathrm{X}$ & - & $\mathrm{X}$ \\
\hline Muquiranã & - & $\mathrm{X}$ & - \\
\hline Pão Duro & - & $\mathrm{X}$ & \\
\hline
\end{tabular}

Fonte: Criado pelas autoras (2020) 


\subsubsection{Mau pagador.}

A questão de $\mathrm{n}^{\circ} 139$ do QSL corresponde ao item lexical mau pagador e na distribuição diatópica na carta L03 apresentou as seguintes variantes:

Figura 04: Ocorrências para o item Mau Pagador

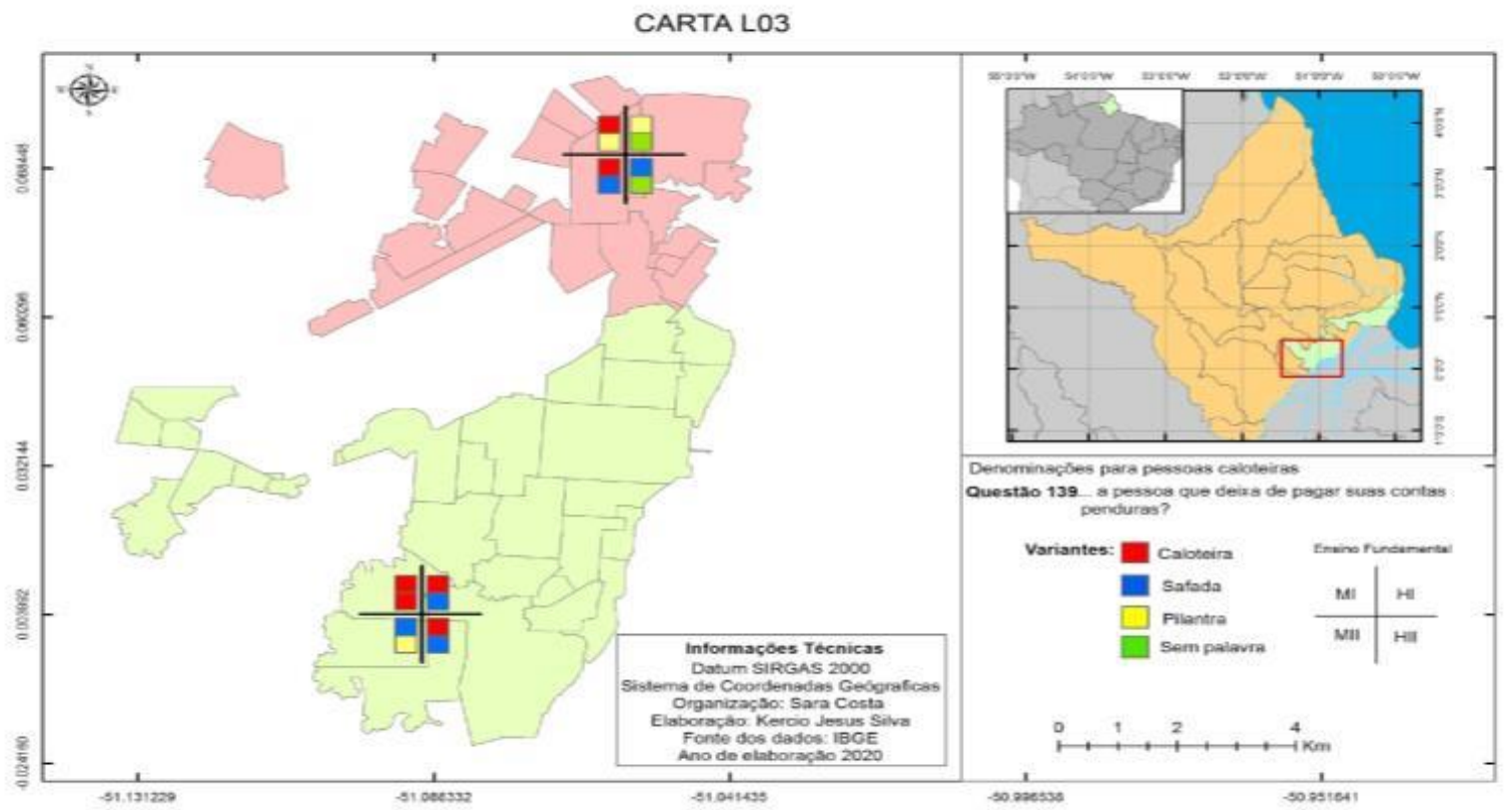

Fonte: criada pelas autoras (2020)

A Carta L03 é relativa à questão 139 do QSL, é bastante produtiva pois foram encontradas 04 (quatro) variantes: Caloteira, Safada, Pilantra e Sem palavra, sendo as 03 (três) últimas diferentes das propostas apresentadas pelo Atlas Linguístico do Amapá. Do ponto de vista do critério da variação diagenérica, para o público feminino destaca-se o uso das variantes, Caloteira 04 (quatro) vezes, Safada 02 (duas) vezes e Pilantra 02 (duas) vezes. Entre os homens os vocábulos Caloteira aparecem 02 (duas) vezes, Pilantra 01 (uma) vez, Sem Palavra 02 (duas) vezes e 03 (três) vezes Safada. A distribuição de acordo com a faixa etária destaca entre os jovens a ocorrência das variantes Caloteira 04 (quatro) vezes e Pilantra 02 (duas) vezes, sendo as mais frequentes, mas os vocábulos Safada ocorre 01 (uma) vez. Entre os idosos a variante que se sobressai é safada, com 04 (quatro) ocorrências, seguida por Caloteira, que aparece 02 (duas) vezes. A variante Sem palavra é usada tanto pelos colaboradores mais jovens quanto os mais idosos, mas ela ocorre apenas 01 (uma) vez, conforme os dados explicitados no quadro 4 :

Quadro 4: Dados comparativos com o ALAP

\begin{tabular}{|c|c|c|c|}
\hline Variantes & ALAP & Zona Sul - Macapá & Zona Norte - Macapá \\
\hline Caloteiro(a) & $\mathrm{X}$ & $\mathrm{X}$ & - \\
\hline Mau Pagador & $\mathrm{X}$ & - & - \\
\hline Velhaco & $\mathrm{X}$ & - & - \\
\hline Enrolão & $\mathrm{X}$ & - & $\mathrm{X}$ \\
\hline Safado(a) & - & $\mathrm{X}$ & $\mathrm{X}$ \\
\hline Pilantra & - & $\mathrm{X}$ & $\mathrm{X}$ \\
\hline Sem Palavra & - & - & \\
\hline
\end{tabular}

Fonte: Criado pelas autoras (2020) 


\subsubsection{Prostituta}

O item prostituta apresentou um total de seis (06) variantes, dispostas a seguir na distribuição diatópica na carta L04:

Figura 05: Ocorrências para o item Prostituta

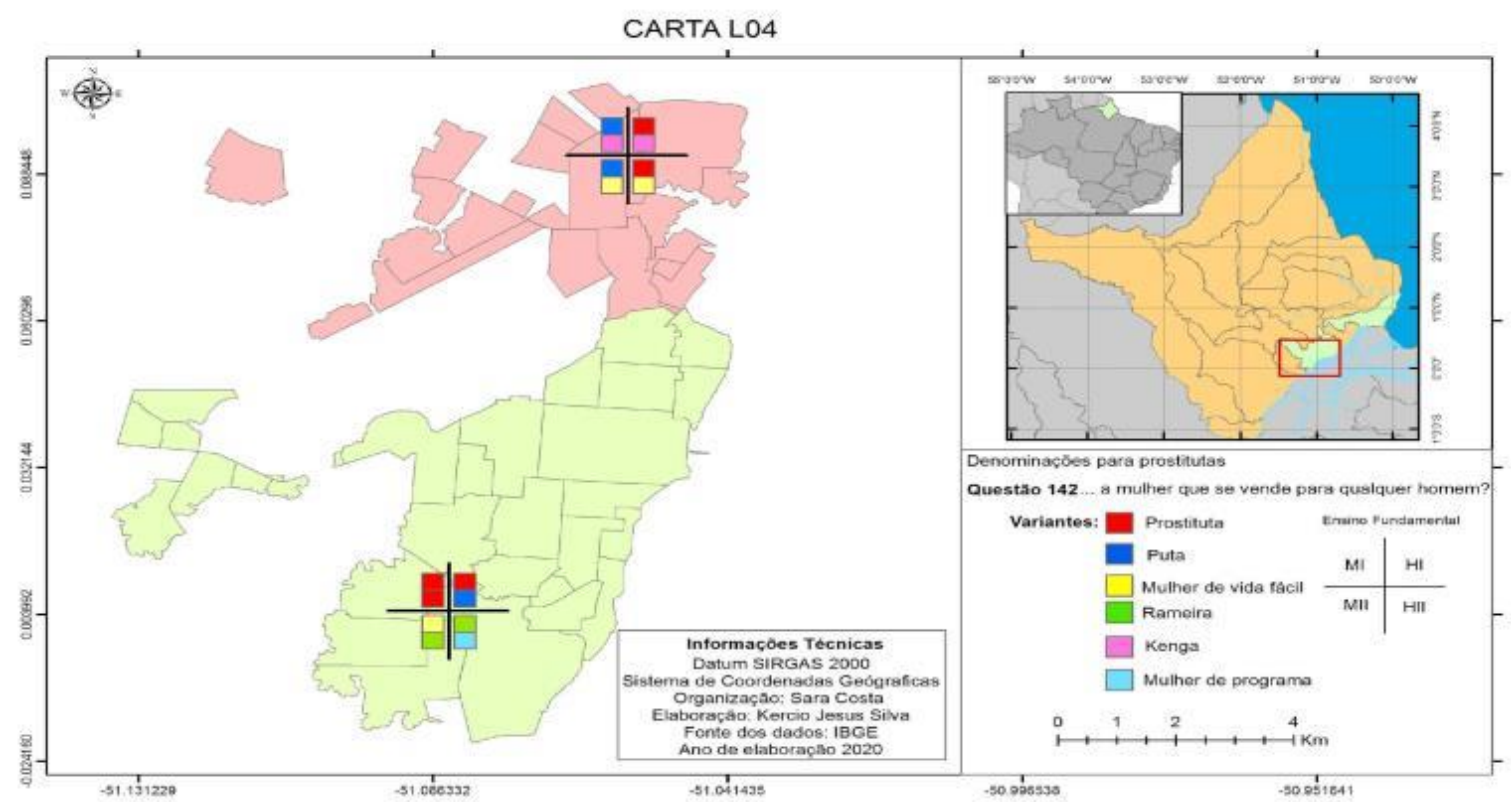

Fonte: criada pelas autoras (2020)

$\mathrm{Na}$ Carta L04, que corresponde a questão 142 do QSL, foram encontradas 06 (seis) variantes, tomando por base a separação diageracional entre a primeira geração o uso da variante Prostituta ocorre 04 (quatro) vezes, Puta 02 (duas) ocorrências e Kenga ocorrendo 02 (duas) vezes, sendo as mais frequentes. Já na segunda geração se sobressaem as variantes: Mulher de vida fácil, se repetindo 03 (três) vezes, RAMEIRA, com 02 (duas) ocorrências, Mulher de Programa Prostituta e Puta, cada uma com apenas 01 (uma) ocorrência. Assim é perceptível que a variante Kenga é exclusiva da primeira geração e Rapariga exclusiva da segunda.

Para a variação diagenérica se obtém duas variantes que entre as mulheres são mais comuns, Prostituta aparecendo 02 (duas) vezes, Puta 02 (duas) vezes, Mulher de Vida Fácil 02 (duas) vezes, Rameira 01 (uma) vez e Kenga 01 (uma) vez. Entre os homens chama a atenção o aparecimento de muitas variantes, mas apenas Prostituta é a que se destaca com 03 (três) ocorrências, Puta aparece 01 (uma) vez, Mulher de Vida Fácil aparece 01 (uma) vez, Rameira aparece 01 (uma) vez, Mulher de Programa é usada 01 (uma) vez. De acordo com o resultado obtido nesse estudo, a variante Mulher de Programa é exclusiva dos homens, as demais foram registradas tanto pelo sexo feminino quanto pelo masculino.

Em comparativo com o ALAP, cabe destacar que as variantes registradas, na maioria, coincidem com as propostas apresentadas entre os estudos. Inclusive, na ordem de produtividade. Os itens coincidentes são, prostituta (como o mais usado), e Puta (como o segundo mais usado) e Kenga. Os não coincidentes são: MULHER DE VIDA FÁCIL, Rameira e MULHER DE PROGRAMA, que são usos que não apareceram na descrição do ALAP; conforme constatação no quadro comparativo de número 5: 
Quadro 5: Dados comparativos com o ALAP

\begin{tabular}{|c|c|c|c|}
\hline Variantes & ALAP & Zona Sul - Macapá & Zona Norte - Macapá \\
\hline Prostituta & $\mathrm{X}$ & $\mathrm{X}$ & $\mathrm{X}$ \\
\hline Puta & $\mathrm{X}$ & $\mathrm{X}$ & $\mathrm{X}$ \\
\hline Kenga & $\mathrm{X}$ & - & - \\
\hline Mulher da Vida & $\mathrm{X}$ & - & - \\
\hline Mulher Solteira & $\mathrm{X}$ & - & - \\
\hline Piriguete & $\mathrm{X}$ & $\mathrm{X}$ & $\mathrm{X}$ \\
\hline Rameira & - & $\mathrm{X}$ & - \\
\hline Mulher de Vida Fácil & - & $\mathrm{X}$ & \\
\hline Mulher de Programa & - & & \multicolumn{2}{c}{} \\
\hline
\end{tabular}

Fonte: Criado pelas autoras (2020).

De modo geral, o estudo buscou evidenciar as distinções entre os dados coletados no ALAP (2017) e a pesquisa de campo de 2020, com o intuito de comparar novas variantes registradas na pesquisa de campo 2020, bem como contribuir com a pesquisa geolinguística no estado do Amapá, fazendo o acréscimo de novas variantes registradas, especificamente no município de Macapá. Sabemos que talvez os dados aqui apresentados sejam ínfimos com relação aos estudos referendados, no entanto, não temos pretensão de esgotá-los e sim de ampliar a pesquisa que teve seu início com o Projeto do Atlas Linguístico do Amapá.

\section{CONSIDERAÇÕES FINAIS}

Mediante os dados aqui representados, mesmo em pequena escala, confirmam um considerado número de lexias divergentes das variantes apresentadas no projeto Atlas Linguística do Amapá. Mesmo o ALAP sendo um projeto tão recente, tendo apenas (03) três anos desde sua publicação, é possível notar que ocorrem algumas variações, que muito provavelmente já eram utilizadas, mas não apareceram ou não foram consideradas tão produtivas na investigação do ALAP. Por outro lado, para três das denominações investigadas não tiveram registradas variantes diferentes das que já são exibidas no referido atlas.

O objetivo principal deste trabalho foi descrever algumas das variantes lexicais que ocorrem no município de Macapá e, posteriormente, comparar com os dados do Atlas Linguístico do Amapá, enfatizar as possíveis variações desde a publicação, onde tão logo se concluímos que os objetivos foram alcançados numa quantidade significativa, haja vista que novas variantes foram descritas no estudo sobre a diversidade linguística do estado do Amapá. E poderão, ainda, servir de aporte bibliográfico para novas pesquisas que venham a acontecer. Além disso, acreditamos que há muito a ser explorado no campo linguístico na cidade de Macapá e, para isso, o Atlas Linguístico do Amapá tem muito a contribuir como base para outros trabalhos assim como este apresentado.

Para além das contribuições científicas essa pesquisa proporciona ao professor atuante na área da língua portuguesa, possibilidades de abordar, em sala de aula, a variação linguística no Amapá de uma perspectiva real, atual e cotidiana dos alunos que como foi comprovado e descrito nessa pesquisa, a variação é algo real e em pleno uso na cidade de Macapá; diferindo do modelo priorizado no ensino da língua portuguesa, baseado apenas na gramática tradicional, que não considera as particularidades linguísticas de cada região e que, geralmente, foge do contexto social da própria clientela escolar. Nesse sentido, utilizar os dados do ALAP é uma possibilidade do aluno se identificar com a língua registrada no uso de outros falantes, ou seja, é trabalhar a ideia de pertencimento e identidade, a partir dos dados linguísticos que caracterizam a sociedade amapaense.

\section{REFERÊNCIAS}

ALKMIM, Tânia Maria. Sociolinguística. Parte I. In: MUSSALIM, Fernanda; BENTES, Ana Cris- 
tina. Introdução à linguística: domínios e fronteiras, v.1, Ged. São Paulo: Cortez, 2006. ATLAS LINGUÍSTICO DO BRASIL (2012) Disponível em: https://alib.ufba.br/. Acesso em 20.01.2018

ATLAS LINGUÍSTICO DO AMAPÁ Disponível em; https://alap.webnode.com.br/ Acesso em 20.01.2018.

CALVET, L. Sociolinguística: uma introdução crítica. Trad. de Marcos Marcionilo. São Paulo: Parábola, 2002.

CARDOSO, S. A. Geolinguística: tradição e modernidade. São Paulo: Parábola, 2010.

CEZÁRIO, Maria Maura \& VOTRE Sebastião. Sociolinguística. In: Manual de Linguística. MARTELOTTA, Mário Eduardo (org.). São Paulo: Contexto, 2008.

COSERIU, E. A geografia linguística. In: COSERIU, E. O homem e sua linguagem. Tradução Carlos Alberto Fonseca e Mário Ferreira. Rio de Janeiro; São Paulo: Presença; USP, 1982. p. 79116.

FERRERA, C; CARDOSO, S. A dialetologia no Brasil. São Paulo: Contexto, 1994.

IBGE. Brasil em Síntese: Panorama Brasil Amapá/Macapá. 2020. Disponível em; https://cidades.ibge.gov.br/brasil/ap/macapa/panorama. Acesso em: 18.08.2020.

LABOV, W. Padrões sociolinguísticos. Trad. de M. Bagno; M. M. P. Scherre; C. R. Cardoso. São Paulo: Ed. Parábola, 2008.

NEVES, M.H.M. O Brasil no contexto da construção de uma identidade linguística no mundo lusófono. In: RIO-TORTO, G.M. et al. (Orgs.) em homenagem ao professor Doutor Mário Vilela. Volume 2. Faculdade de Letras da Universidade do Porto. 2005. p. 643-656.

RAZKY, A; RIBEIRO, C; SANCHES, R. O Projeto Atlas Linguístico do Amapá (ALAP): Caminhos Percorridos E Estágio Atual. Alfa, São Paulo v.61, n.2, p.303-317, 2017.

SANCHES, R; SILVA, M.; Variação Semântico-Lexical No Amapá. Revista Linguística/ Revista do Programa de Pós-Graduação em Linguística da Universidade Federal do Rio de Janeiro. Volume 10, número 1, junho de 2014.

TARALLO, F. A Pesquisa Sociolinguística. São Paulo: Editora Ática, 2005. 